\title{
PAPESCA/UFRJ: Aprendizados de uma década de dialogicidade entre universidade e comunidade
}

\author{
PAPESCA/UFRJ: Learning a decade of dialogicity between university and community
}

\author{
Diego Correia de Souza ${ }^{1}$ \\ Luiz Felipe A. Santos ${ }^{2}$ \\ Sidney Lianza ${ }^{3}$
}

Artigo recebido para publicação em jan./2015 e aceito para publicação em mai./2015

\section{RESUMO}

Com origem em 2004, no município de Macaé-RJ, o Programa "Pesquisa Ação na Cadeia Produtiva da Pesca Artesanal e Aquicultura Familiar no Litoral Fluminense (PAPESCA/UFRJ)" desenvolveu, ao longo de dez anos, ações em várias regiões do litoral fluminense. Desde seu início, a PAPESCA/UFRJ, ampliou atividades interdisciplinares e atuou nas dimensões de extensão, pesquisa e ensino, desenvolvendo conhecimento e políticas públicas que envolvem atores das populações tradicionais de maneira dialógica em parceria com diversas instituições (universidades, institutos de pesquisas, escolas técnicas, ONGs, entidades de classe, movimentos sociais e governos na esfera municipal, estadual e federal). Os projetos gerados na PAPESCA/UFRJ apoiam-se no campo da Pesquisa - ação. O objetivo desta publicação é relatar o aprendizado ao longo de uma década de atuação e disponibilizar estas experiências para a comunidade acadêmica, entre outros setores da sociedade. Os principais objetivos do Programa são: orientar e elaborar respostas para a sustentabilidade no âmbito da sociedade e do meio ambiente sobre o setor da pesca artesanal e aquicultura familiar, fortalecendo elos da economia social e solidária, promovendo o assessoramento dialógico entre as populações tradicionais e atores intervenientes, sem desprezar a política de gênero e a participação equitativa entre técnico e atores comunitários.

Palavras-chave: Extensão universitária; Pesca Artesanal, Aquicultura Familiar, Economia solidária, Pesquisa-ação.

\begin{abstract}
Originating in 2004 in the city of Macaé, Rio de Janeiro, the program "Action Research in the Production Chain of Artisanal Fisheries and family Aquaculture in Fluminense coastal (PAPESCA/UFRJ)" developed over ten years of actions in various regions of Rio de Janeiro coast. Since its inception, PAPESCA/UFRJ, expanded interdisciplinary activities and served in the range of dimensions, research and teaching, developing knowledge and public policy involving actors of traditional populations in a dialogically manner; in partnership with various institutions (universities, research institutes, technical schools, ONGs, trade unions, social movements and government spheres). The projects generated in PAPESCA / UFRJ support itself in the field of action -research. The purpose of this publication is to report the learning over a decade of expertise and provide these experiences to the academic community, and other sectors of society. The program aims to guide and prepare answers for sustainability in society and environment on the artisanal fisheries sector and family aquaculture, strengthening links in the social and solidarity economy, promoting dialogical advice between traditional populations and social actors without despise the gender policy and equal

\footnotetext{
${ }^{1}$ Acadêmico do Curso de Engenharia da Produção da Escola Politécnica da UFRJ (CEP/POLI/UFRJ); bolsista desde 2013 do Núcleo de Solidariedade Técnica/UFRJ (SOLTEC/UFRJ) no Programa de Pesquisa Ação da Cadeia Produtiva da Pesca Artesanal no Litoral Fluminense (PAPESCA); Técnico em Meio Ambiente pelo IFRJ

${ }^{2}$ Acadêmico do CEP/POLI/UFRJ, bolsista desde 2014 do SOLTEC/UFRJ na PAPESCA/UFRJ

${ }^{3}$ Professor Associado do CEP/POLI/UFRJ, doutor em Engenharia de Produção, coordenador da PAPESCAUFRJ do SOLTEC/UFRJ
} 
Revista Tecnologia e Sociedade, Curitiba, v. 11, n. 22, 2015

Edição Especial XII Encontro Nacional de Engenharia e Desenvolvimento Social

ISSN (versão online): 1984-3526

ISSN (versão impressa): 1809-0044

participation between technical and community actors.

Keywords: Continuing education; Artisanal Fisheries, Aquaculture Family, Solidarity economy, action research.

\section{INTRODUÇÃO}

Os dados oficiais do Ministério da Pesca e Aquicultura estima que haja, na atividade da pesca artesanal no Brasil, aproximadamente 2 milhões de trabalhadores, e que o setor seria responsável por aproximadamente $45 \%$ da produção de pescado do país. Haveria 957 mil pescadores organizados em 1.200 colônias, 760 associações, 137 sindicatos e 47 cooperativas. Mesmo assim, um dos maiores desafios da pesca artesanal está relacionado à participação dos pescadores nas organizações sociais, ao alto grau de analfabetismo e baixa escolaridade, ao desconhecimento da legislação na base, os mecanismos de gestão compartilhada e participativa da pesca (MPA, 2009). Esses dados são extremamente polêmicos, não havendo consenso nem no ambiente acadêmico nem junto às organizações representativas dos pescadores e pescadoras. Eles formam um contingente de trabalhadores ainda excluídos do sistema econômico capitalista atual e, muitas vezes, buscam no associativismo ou cooperativismo uma forma importante para protagonismo social e econômico e a garantia de renda e manutenção de suas famílias (MALDONADO \& SANTOS, 2006).

A PAPESCA/UFRJ observa que, no Brasil e no mundo, as cadeias produtivas da pesca artesanal e da aquicultura familiar estão colocadas sob ameaça devido à extração de recursos naturais não renováveis com objetivos econômicos acima dos parâmetros enunciados pela prudência ecológica. Do ponto de vista social, as comunidades de pescadores artesanais estão entre as mais desfavorecidas do Brasil. Apesar desse cenário, a atividade pesqueira continua atraindo novos contingentes de trabalhadores desempregados que aproveitam a - aparente "facilidade" de inserção nessa prática como um caminho para buscar sustento e renda. Por esse poder de atração, vem se perpetuando um encontro conturbado entre o aumento progressivo do número de pescadores e fatores como a diminuição do estoque pesqueiro, cujas causas estão no próprio deslocamento de trabalhadores de outros setores para a pesca, a exploração de petróleo e gás em águas profundas, 
Revista Tecnologia e Sociedade, Curitiba, v. 11, n. 22, 2015

Edição Especial XII Encontro Nacional de Engenharia e Desenvolvimento Social

ISSN (versão online): 1984-3526

ISSN (versão impressa): 1809-0044

a especulação imobiliária, a ausência de saneamento básico, a pesca industrial de grande porte e os mecanismos desiguais de regulação da cadeia produtiva da pesca.

Denota-se, ainda, que os resultados das pesquisas desenvolvidas até o momento são discretos e aquém do fomento de políticas públicas capazes de lograr êxito na sustentabilidade da cadeia produtiva da pesca artesanal, da aquicultura familiar e à preservação dos saberes tradicionais. Considerada a atualidade de pressões ou mesmo expulsões de comunidades tradicionais de seus territórios - por meio da especulação imobiliária ou por desistência de atividades profissionais e culturais consuetudinária. As comunidades - que verifica-se em muitos casos, organizam-se segundo uma conjugação de famílias de pescadores tradicionais e novas famílias pesqueiras - permanecem atreladas a um círculo de pobreza cada vez mais acentuado. Por outro lado, as atividades de aquicultura, de produção e de inovação tecnológica em processamento de pescado carecem de formação, assessoria técnica e econômica que atenda às características sociais e ambientais de cada região, considerando as especificidades apresentadas.

As universidades públicas, como entes do Estado, podem atuar nas diversas comunidades de pesca artesanal, construindo de forma conjunta e dialógica projetos de políticas públicas. Infelizmente, nota-se no cenário nacional, uma precariedade de ações acadêmicas nas demandas sociais, demonstrando claramente o pouco apreço pelas atividades extensionistas e uma vocação quase que exclusiva ao campo mercadológico e corporativista orientada pelos investimentos de recursos e parcerias público/privadas.

A PAPESCA no contra fluxo desta situação, vem durante uma década, construindo e aprendendo com suas experiências extensionistas de formação discente e também do corpo técnico. Através destas, é possível apontar a fundamental importância do empoderamento das comunidades, a dialogicidade e a utilização de metodologias participativas, não só com as comunidades em questão, mas com diversos setores da sociedade que se relacionam direta ou indiretamente com a pesca artesanal. O objetivo deste artigo é relatar a experiência condensada ao longo desta década de trabalho focado em comunidades pesqueiras do estado do Rio de Janeiro. 


\section{IDENTIDADE PAPESCA - HISTÓRICO E VALORES}

Em abril de 2004 surge o então Projeto "Pesquisa-Ação na Cadeia Produtiva da Pesca em Macaé" criado a partir da parceria entre o Núcleo de Solidariedade Técnica (SOLTEC/UFRJ), o Pólo Náutico/UFRJ e o Núcleo de Pesquisa Ecológica de Macaé (NUPEM/UFRJ). Seu objetivo foi o de contribuir para a sustentabilidade da cadeia produtiva da pesca artesanal e da Escola Municipal de Pescadores, visando o desenvolvimento local social e solidário. Durante os dois primeiros anos, o projeto contou com o apoio da Financiadora de Estudos e Projetos (FINEP).

Desde a fase inicial, os projetos desenvolvidos pelo processo de criação do Programa que hoje intitula-se PAPESCA/UFRJ adotaram como estratégia metodológica a Pesquisa Ação, sem prescindir de outras metodologias, observadas tanto no domínio teórico, quanto no contexto empírico. Trabalhar em redes de cooperação de pesquisa informativa tecnológica, de sorte a fazer frente aos entraves na sustentabilidade das cadeias produtivas nos territórios delimitados em que atua. Priorizando a orientação pelos princípios de economia solidária.

O Programa PAPESCA/UFRJ preconiza a interdisciplinaridade e reconhece a indissociabilidade das atividades de ensino, pesquisa e extensão universitária, favorecendo um ambiente de geração e aplicação do conhecimento, por meio de diálogo constante com a realidade humana e ambiental. Responde, na medida de seu alcance, às demandas sociais, conjuntamente com a formação sociotécnica de estudantes de graduação, seja na disciplina de extensão vinculada ao Programa, seja nos estudos de caso ou pesquisas informativas, analíticas ou aplicadas, desenvolvidas durante as orientações. Tal percurso têm mostrado-se bastante laborioso, mas, em contrapartida, gera resultados na produção de conhecimento e na formação de profissionais, contribuindo com a indicação de metas a serem perseguidas pela Universidade Pública, em via de mão dupla entre a Universidade e a Sociedade.

O desenvolvimento das ações da PAPESCA na região renderam diversos frutos, dos quais podemos elencar: (a) criação da Escola Municipal de Pescadores (2002) pela Prefeitura de Macaé, em parceria com a UFRJ, uma escola de formação politécnica de nível fundamental cujo objetivo pautava-se no fortalecimento da 
Revista Tecnologia e Sociedade, Curitiba, v. 11, n. 22, 2015

Edição Especial XII Encontro Nacional de Engenharia e Desenvolvimento Social

ISSN (versão online): 1984-3526

ISSN (versão impressa): 1809-0044

atividade pesqueira na região. Para tanto, a UFRJ oferecia disciplinas complementares como Ecologia, Construção Naval, Aquicultura, Relações Socioambientais, Prática de Comunicação Social entre outras; (b) interferência nas políticas públicas locais através da parceria estabelecida com a Prefeitura Municipal, resultando na inclusão do capítulo sobre a pesca no Plano Diretor da cidade de Macaé; (c) incubação de um empreendimento econômico solidário de beneficiamento de pescados (BENESCA), iniciado em 2005, com recursos advindos de edital FINEP; (d) proposição de pauta educacional que englobava o ensino fundamental, médio, técnico, educação de jovens e adultos, qualificação profissional articulado à construção de um complexo de infraestrutura, curso de graduação e de pós-graduação, por meio da elaboração de projeto Tripartite (parceria entre Prefeitura de Macaé, PAPESCA/UFRJ e PETROBRAS). Em 2006, o diálogo com outros projetos e iniciativas apresentou uma demanda importante vinda de Minas Gerais, que culminou com a elaboração de seminários conjuntamente com outros projetos, como o Peixe, Pessoas e Água, sustentando a reflexão sobre a abrangência territorial de sua atuação.

A PAPESCA/UFRJ, durante os anos de 2006 a 2010, manteve intercâmbio com três países, em três continentes distintos. A saber Portugal, Canadá e Moçambique. Em Portugal, entre 2006 e 2007, foram realizadas três missões. As duas primeiras visaram intercâmbio acadêmico com o Socius - Centro de Investigação em Sociologia Econômica e das Organizações, do Instituto de Estudos sobre Gestão da Universidade Técnica de Lisboa. Ampliando os espaços de diálogo e de produção acadêmica com a participação em Seminário na Universidade de Algarve. A terceira incursão diz respeito à participação no seminário sobre desenvolvimento local em comunidades ribeirinhas em Sesimbra, com importantes observações sobre a construção de pólos de pesca, fortemente apoiados pelo Estado português.

Incursionou-se também no continente Americano durante os anos de 2007 e 2008. No Canadá o coordenador do PAPESCA/UFRJ atendendo ao convite do Centro de Assentamentos Humanos da Universidade British Columbia, de Vancouver, atuou como professor convidado, em pesquisa sobre gestões consorciadas e gestão compartilhada de recursos naturais - commons. 
Revista Tecnologia e Sociedade, Curitiba, v. 11, n. 22, 2015

Edição Especial XII Encontro Nacional de Engenharia e Desenvolvimento Social

ISSN (versão online): 1984-3526

ISSN (versão impressa): 1809-0044

Em 2010, a ação da PAPESCA/UFRJ em Moçambique, no continente Africano, propiciou uma missão do Ministério da Pesca e Aquicultura do Brasil, em parceria com o Ministério das Pescas de Moçambique, onde o coordenador do projeto representou a Rede Solidária da Pesca. Na ocasião, foi assinado o Termo de Cooperação Técnica entre os governos do Brasil e de Moçambique, que seria financiado pela Agência Brasileira de Cooperação. Tal projeto encontra-se ainda em suspenso e, tal colaboração, sem explicações consistentes por parte dos órgãos governamentais, nunca saiu do papel.

\section{EXPERIÊNCIAS COM A PESQUISA-AÇÃO}

O desenvolvimento da PAPESCA/UFRJ teve início em 2004, no município de Macaé, com um diagnóstico participativo que visava à identificação dos entraves socioambientais e dos problemas nas condições de vida e trabalho dos envolvidos na cadeia produtiva da pesca, como um Projeto do Núcleo de Solidariedade Técnica (SOLTEC/UFRJ) e, neste ambiente, revestiu-se dos mesmos parâmetros ideológicos, teóricos e metodológicos do núcleo.

O SOLTEC é um Programa da Pró-Reitoria de Extensão da Universidade Federal do Rio de Janeiro - UFRJ e se constitui em um grupo interdisciplinar de extensão, pesquisa e ensino. Fundado em 13 de março de 2003, fruto de uma mobilização de estudantes e de professores da Escola Politécnica da UFRJ, envolvidos em projetos de promoção de direitos sociais. A ideia evoluiu e, com ela a decisão de se construir um núcleo no Centro de Tecnologia, que propiciasse operações de apoio técnico a empreendimentos voltados para a inclusão social.

O Programa PAPESCA/UFRJ tem hoje o Núcleo de Solidariedade Técnica como seu maior aliado institucional, somando a intensa colaboração do Núcleo Interdisciplinar UFRJMar, do Laboratório de Tecnologia de Alimentos da Escola de Química, do Núcleo em Ecologia e Desenvolvimento Socioambiental de Macaé (NUPEM-UFRJ Campus Macaé). Todos inseridos no órgão suplementar do Centro de Tecnologia - Núcleo Interdisciplinar para o Desenvolvimento Social NIDES/UFRJ.

A adoção dos métodos da pesquisa-ação foi resultado da convicção da 
Revista Tecnologia e Sociedade, Curitiba, v. 11, n. 22, 2015

Edição Especial XII Encontro Nacional de Engenharia e Desenvolvimento Social

ISSN (versão online): 1984-3526

ISSN (versão impressa): 1809-0044

equipe de que qualquer tipo de ação transformadora deva ser fruto de uma reflexão coletiva e realizada de forma participativa. Desta forma, esta estratégia metodológica pode propiciar mobilização dos atores e trazer elementos de consciência e seus métodos também podem propiciar contextos adequados para ações transformadoras, tanto durante, quanto posteriormente à pesquisa. Os pesquisadores inserem-se inclusive como atores do processo: "a pesquisa-ação, com objetivo emancipatório e transformador do discurso, das condutas e das relações sociais, vai mais longe do que a abordagem Lewiniana (THIOLLENT, 1996) essencialmente democrática e tendo a mudança como finalidade e exige que os pesquisadores se impliquem como atores" (MORIN, 2004:55) (parênteses nossos).

No longo processo de fundamentação teórica da equipe de pesquisa, baseado em oficinas metodológicas, foram colocadas em debate as noções de Capital Social, Resiliência, Ecodesenvolvimento, Políticas Públicas, Gestão Compartilhada de Recursos Naturais, entre outros. De forma que os objetivos levaram a uma adequação da PAPESCA/UFRJ para contribuir com a gestão compartilhada da pesca artesanal e da aquicultura familiar no litoral fluminense, articulando tanto no âmbito estadual como a nível nacional a Rede Solidária da Pesca.

A metodologia de pesquisa-ação, denominado pela sigla PAR (participatory and action research), pressupõe o diálogo entre o pesquisador (conhecimento técnico) e o ator social (conhecimento tácito ou consuetudinário), busca-se de maneira permanente a implicação dos atores sociais na pesquisa. Trata-se de uma metodologia em que, segundo Desroche (2006), o pesquisador tenderia a se transformar em ator social, enquanto este tenderia a se transformar em pesquisador.

Também, no trajeto da PAPESCA/UFRJ incorporou-se uma 'máxima' utilizada por Simoni (2002) na qual se procura estimular estudantes e pesquisadores (principalmente da Engenharia de Produção), que almejam trabalhar com populações marginalizadas, a sair de seus laboratórios, afirmando que: 'é preciso ir lá para ver, é preciso ir lá para viver, é preciso ir lá para ver com os olhos dos outros'.

A Pesquisa-Ação pressupõe não apenas o desenvolvimento conceitual metodológico, mas também a mudanças de atitudes (MORIN, 2004; THIOLLENT, 1996). Com essa compreensão, passa-se a adotar o princípio de que não adianta 
Revista Tecnologia e Sociedade, Curitiba, v. 11, n. 22, 2015

Edição Especial XII Encontro Nacional de Engenharia e Desenvolvimento Social

ISSN (versão online): 1984-3526

ISSN (versão impressa): 1809-0044

apenas analisar a cadeia produtiva da pesca ou as questões ambientais a partir das salas de aula ou dos laboratórios da UFRJ. É necessário assumir o compromisso de conhecer a realidade para transformá-la. A isonomia estabelecida entre o saber tradicional e o saber acadêmico implica um contrato entre as partes de modo que os objetivos e prioridades consensualmente definidos sejam alcançados.

O projeto educacional parte também de sua identificação com o movimento da Economia Solidária, portanto, se vê engajado no processo de construção de uma sociedade, que implica na necessidade de erigir "novos valores, acentuando (assim) o papel da educação em seu caráter participativo, contestatório, alterativo. A economia solidária dessa forma é também uma práxis pedagógica" (GADOTTI, 2009:23) que pretende uma das mais importantes práticas educativas: propiciar que os trabalhadores ensaiem a "experiência profunda de assumir-se. Assumir-se como ser social e histórico como ser pensante, comunicante, transformador, criador e realizador de sonhos" (FREIRE, 2007;41).

Essa práxis pedagógica implica num percurso metodológico que possua como características imanentes: o diálogo entre os saberes; a negociação contínua entre educandos e educadores; a interação entre teoria e prática, entre processos formativos em sala de aula e no campo de trabalho; a sistematização crítica dos atores do processo, sobre seus desejos e intenções, suas histórias individuais e das comunidades, suas demandas e expectativas, sobre o monitoramento e as avaliações de processos. Tal práxis pedagógica é incontornável e necessita da sistematização como elemento chave para descrição do processo em construção.

Principia a Pesquisa-Ação a inserção dos pesquisadores no seio da comunidade a ser estudada, em observações diretas do cotidiano das pessoas e da escuta de suas demandas. Em tal etapa, os procedimentos metodológicos qualitativos, desenvolvidos pelas Ciências Sociais, revelam grande eficácia, especialmente à Etnografia, à História Oral e aos métodos imagéticos de pesquisa mais conhecidos pela Antropologia Visual. A possibilidade de se realizarem registros fotográficos e videográficos das atividades laborais próprias às artes da pesca e ao beneficiamento do pescado permite uma observação em diferido e repetida, propiciando uma percepção mais aguda e um melhor entendimento destas atividades. O material visual e audiovisual produzido é organizado de modo a se tornar um aporte de memória que pode ser [re]visitado pelos pesquisadores e pelos 
Revista Tecnologia e Sociedade, Curitiba, v. 11, n. 22, 2015

Edição Especial XII Encontro Nacional de Engenharia e Desenvolvimento Social

ISSN (versão online): 1984-3526

ISSN (versão impressa): 1809-0044

atores envolvidos, sejam eles a própria comunidade ou o público em geral. Promovendo, simultaneamente, o diálogo esclarecedor, dirimindo dúvidas e norteando novas etapas de investigação. O material fotográfico e audiovisual pode também servir de base documental para posteriores produções multimídia.

A PAPESCA/UFRJ há dois anos, definiu o processo de implantação da Reserva Extrativista (RESEX) de Itaipu, no município de Niterói, Rio de Janeiro, como prioridade de sua atuação, decorrente do desafio colocado pela complexidade sociocultural e de os imanentes conflitos socioambientais apresentados. Abrem-se dessa maneira, uma extraordinária oportunidade para o exercício das metodologias participativas.

O conhecimento da realidade e das demandas das comunidades ali existentes, incluindo aquelas que compõem os arredores da área demarcada caiçaras, quilombolas e indígenas - exigem, como parte do desenvolvimento da pesquisa ação, uma prolongada inserção no ambiente do território e um convívio o mais próximo possível com as populações tradicionais ali existentes. Os estudantes bolsistas participam, além da disciplina de extensão cursada no campus universitário, de vivências no âmbito destas comunidades, praticando a observação direta, realizando entrevistas com a comunidade e vivenciando a realidade local. Com o objetivo de facilitar a permanência da equipe técnica e prover um ambiente no local para a sistematização das informações, os coordenadores alugarem, por conta própria, um pequeno local para estadia no centro da Vila dos Pescadores de Itaipu.

As RESEXs, por determinação legal, devem possuir um Conselho Deliberativo com maioria simples de representantes da população tradicional local, os pescadores artesanais, no caso de Itaipu. Isso demanda, portanto, que todos os projetos, estejam focados no monitoramento, na avaliação de manejo e sejam realizados numa sintonia fina entre técnicos, comunidade e outras instituições ali presentes. Enfatiza-se que todos os aspectos são consensualizados coletivamente, seja na execução das metas previstas, na organização e na coordenação das equipes de trabalho, na adequação de infraestrutura e logística e na adequação da metodologia.

O emprego de questionários com questões objetivas quantificáveis e questões abertas acenou possíveis marcadores a serem observados que ganharam 
Revista Tecnologia e Sociedade, Curitiba, v. 11, n. 22, 2015

Edição Especial XII Encontro Nacional de Engenharia e Desenvolvimento Social

ISSN (versão online): 1984-3526

ISSN (versão impressa): 1809-0044

corpo com a primeira grande atividade negociada com a comunidade da Vila dos Pescadores de Itaipu: o curso sobre Gestão de Projetos Solidários. Os participantes, os objetivos, o plano de estudos, o trabalho de campo, a avaliação, tudo sem exceção foi motivo de discussão e negociação entre os trabalhadores técnicos e estudantes da PAPESCA/UFRJ com os pescadores e comunitários da Vila de Itaipu. Esse percurso de seis meses propiciou pertencimento e emponderamento dialógico aos participantes. A comunidade participou do curso, num total de doze pessoas; pescadores das diversas modalidades, marisqueiros, comerciantes e empreendedores locais apresentaram seus próprios pontos de vista através de estudos de caso expostos em banners, cuja confecção foi elaborada, em cada detalhe, por técnicos e comunitários através de formações específicas em colaboração com outros projetos do próprio SOLTEC, como LIPE - Laboratório de Informática para a Educação e TIFS - Tecnologia da Informação para Fins Sociais. Os estudos de caso versaram sobre a cadeia produtiva da mariscagem; sobre as técnicas de pesca prevalentes naquela região, sobre a visão dos pescadores e sobre o Museu de Arqueologia.

Tal processo ensejou que a maioria absoluta dos participantes do curso de Gestão de Projetos Solidários integre uma equipe que se forja num contínuo projeto de formação de formadores, ou seja, multiplicadores de conhecimentos que visa o empoderamento de pescadores e comunitários da Vila dos Pescadores de Itaipu e de Piratininga nos desdobramentos referentes a implantação da Reserva Extrativista que afeta diretamente um número estimado de 150 pescadores e pescadoras.

Esse empoderamento terá em seu processo e em sua finalidade contribuir com que a população tradicional influa de maneira decisiva na definição do Acordo de Gestão da RESEX a ser aprovado pelo seu Conselho Deliberativo.

\section{AÇÕES NOS TERRITÓRIOS}

Entre 2004 e 2009, a atuação principal da PAPESCA/UFRJ foi no Município de Macaé. Desde 2010, no entanto, o programa focalizou suas ações nos territórios de Itaipu, região litorânea de Niterói, na Praia da Raza, no município de Búzios e na Costa Verde que compreende Ilha Grande, Angra dos Reis e Paraty. Tais atuações atenderam às demandas dos próprios pescadores em seus anseios por aperfeiçoar 
Revista Tecnologia e Sociedade, Curitiba, v. 11, n. 22, 2015

Edição Especial XII Encontro Nacional de Engenharia e Desenvolvimento Social

ISSN (versão online): 1984-3526

ISSN (versão impressa): 1809-0044

sua organização interna enquanto movimento social, assim como se qualificar para: a gestão compartilhada dos recursos naturais; a aquisição de competências técnicas para o beneficiamento do pescado e o aprimoramento da arte da pesca; a constituição e o desenvolvimento de uma economia sustentável e solidária; a articulação com as diversas instâncias do poder público e agentes de políticas públicas; e o desenvolvimento do bem viver comunitário.

As atividades do Programa PAPESCA/UFRJ privilegiam a visibilidade e 0 empoderamento das comunidades pesqueiras. Dentre estas, destacam-se:

- ações na educação continuada, sejam na oferta de educação pública, projetos especiais e profissionalizantes que permitam ancorar as ações na prática;

- articulação com outros canais de discussão como a Rede Solidária da Pesca no Litoral Fluminense e a Rede de Assessoria em Extensão Pesqueira Sul/Sudeste;

- incentivo a projetos e ações que visem à manutenção e produção cultural da identidade de pesca;

- cooperação SOLTEC/PAPESCA com as comunidades por meio do SENAES na criação e no desenvolvimento de uma identidade cultural em Paraty, na Costa Verde Fluminense;

- mobilização do poder público na elaboração de diagnósticos participativos;

- densibilização com a retomada de trabalhos pretéritos da PAPESCA/UFRJ;

- mapeamento de ações voltadas às políticas de saúde e previdência social dos pescadores, marisqueiros, descascadeiras e outros profissionais ligados à pesca;

- mobilização dos pescadores a participarem de fóruns, conselho, comitês e subcomitês, fomentando o acesso destes atores a questões técnicas específicas.

A partir de 2012, o território localizado no Canto de Itaipu (Vila dos Pescadores de Itaipu) Niterói, transformou-se na prioridade da PAPESCA/UFRJ, é onde tem concentrado suas ações. A escolha de Itaipu responde a uma demanda dos próprios pescadores no que tange à reclamação da constante "pesca" de resíduos sólidos feita por suas redes. Já era fato a importância da pesca artesanal - 
Revista Tecnologia e Sociedade, Curitiba, v. 11, n. 22, 2015

Edição Especial XII Encontro Nacional de Engenharia e Desenvolvimento Social

ISSN (versão online): 1984-3526

ISSN (versão impressa): 1809-0044

seja no que se refere a economia e cultura e era do interesse da equipe do projeto pesquisar o quanto o problema ambiental impactaria na vida da pesca artesanal na região.

O reconhecimento do território e dos principais atores sociais de Itaipu foi um processo lento, presencial e extremamente dialógico. A região tem um histórico de forte colaboração com a Universidade Federal Fluminense (UFF), a qual já desenvolveu ações de pesquisa em defesa da comunidade local, além de outras ações acadêmicas, principalmente nos campos da antropologia e biologia marinha, contando com cerca de três décadas de trabalho.

Apesar do histórico positivo da UFF em Itaipu, a comunidade dos pescadores é constante alvo de pesquisas acadêmicas nas quais nem sempre se prevê, por parte dos pesquisadores, uma devolutiva em benefício da comunidade. Tais incursões levaram a um desgaste da confiança dos pescadores e comunitários de Itaipu em relação à academia. O distanciamento constatado no início de nossas tentativas de aproximação com a comunidade local, certamente expressa o resultado desta dinâmica.

Porém, com ações contínuas de diálogo, com intuito de conhecer a complexidade das relações entre os diversos atores sociais da região e sua referência cultural com a terra, aos poucos foi possível estabelecer laços de confiança. Este processo durou cerca de um ano e mostrou uma região com intensos conflitos sociais e ambientais. Em relação aos atores sociais, os entraves eram bastante complexos e se pode perceber que a maioria dos pescadores artesanais eram desarticulados do coletivo, trabalhando muitas vezes individualmente e compartilhando os problemas dos demais. As lideranças locais (praticamente do gênero masculino) organizavam-se em uma Associação, que apesar da fragilidade institucional representava importante centro de articulação e referência.

O contato com as principais lideranças da Colônia de Pescadores da região deu-se em diversas abordagens, porém não se obteve muito sucesso desdobrado em ações conjuntas. Observamos também (por meio das entrevistas dirigidas ou abertas e também nos relatórios individuais de observação) a interferência da problemática da pesca industrial na região. Não havia nenhuma fiscalização por meio de qualquer órgão regulador, seja ele local, estadual ou federal neste 
Revista Tecnologia e Sociedade, Curitiba, v. 11, n. 22, 2015

Edição Especial XII Encontro Nacional de Engenharia e Desenvolvimento Social

ISSN (versão online): 1984-3526

ISSN (versão impressa): 1809-0044

segmento e tal atividade prejudicava (e prejudica) o trabalho da pesca artesanal na região, seja porque as embarcações danificam as redes de pesca, seja porque interferem no estoque dos cardumes locais.

Em meio a todo esse processo, foram liberadas as obras do Complexo Petroquímico do Rio de Janeiro (COMPERJ) cujos dutos lançariam rejeitos do processamento de petróleo na praia de Itaipuaçu, localizada no município de Maricá, vizinho a Itacoatiara e Itaipu e que afeta diretamente toda a dinâmica da atividade pesqueira no local, seja pelo "bota fora" gerado pelos dutos, seja pelo fundeio de embarcações e plataformas. Este processo gerou extrema polêmica, pois a proposta inicial da extensão do duto na praia era de poucos quilômetros da costa, podendo causar danos irreparáveis a prática da pesca artesanal.

Outra ação de extrema relevância, que aconteceu em Itaipu, foi a implantação da Reserva Extrativista Marinha (RESEX), em 30 de setembro de 2013, através de Decreto do Governo do Estado do Rio de Janeiro, na qual tinha como objetivo regulamentar a área de proteção da pesca artesanal e criar acordos de gestão para a pesca na região. O processo de implementação da RESEX ficou a cargo do Instituto Estadual do Ambiente (INEA). A PAPESCA/UFRJ, entendendo a importância deste acontecimento para a região, decidiu acompanhar os trâmites de tal processo.

As primeiras reuniões nas quais a equipe da PAPESCA participou foram as que tinham como objetivo a formação do Conselho Deliberativo da RESEX, que deve ser constituído por $50 \%$ de pescadores artesanais e demais membros da sociedade civil e organizada e da esfera pública. Esse foi um momento importante para a PAPESCA/UFRJ definir sua atuação na região, e definiu-se como principal objetivo a assessoria aos pescadores artesanais, principalmente para aqueles focados na composição do Conselho Deliberativo.

Ao longo da trajetória da PAPESCA/UFRJ na região, foram constituídas importantes parcerias que se tornaram fundamentais para o desenvolvimento das ações locais. Podem ser citados os comerciantes, empreendedores e donos de pequenos restaurantes da região, que nos cederam gentilmente espaços dos seus estabelecimentos para realização de oficinas e reuniões. A parceria com o Museu de Arqueologia de Itaipu, que através de seus representantes participa ativamente de diversas atividades conjuntas, como seminários, reuniões, oficinas, além de ceder 
Revista Tecnologia e Sociedade, Curitiba, v. 11, n. 22, 2015

Edição Especial XII Encontro Nacional de Engenharia e Desenvolvimento Social

ISSN (versão online): 1984-3526

ISSN (versão impressa): 1809-0044

gentilmente os espaços para os eventos, apresentando um trabalho realmente de portas abertas para a comunidade e principalmente para os pescadores artesanais de Itaipu.

Apesar de limitação de recursos, a PAPESCA/UFRJ tem desenvolvido ações que visam a "formação de formadores" dos moradores da vila de Itaipu, com foco nos pescadores artesanais participantes do Conselho Deliberativo da RESEX. Apesar dos conflitos e desafios já citados e de outros de imensa gravidade (como a situação a irregular fundiária da parte majoritária dos moradores da vila, alvo de grande especulação imobiliária) é possível observar que a PAPESCA/UFRJ vem desempenhando um importante papel na mobilização e na formação da população tradicional de Itaipu. Oficinas e cursos sobre diversas temáticas como boas práticas do pescado, beneficiamento do pescado e gestão de projetos solidários foram realizados com ampla participação e protagonismo dos pescadores artesanais e moradores de Itaipu envolvidos na cadeia produtiva da pesca. Uma das ações fundamentais para que todo esse processo fosse facilitado foi o aluguel de uma casa na região, onde foi possível uma grande imersão e maior contato com a população local.

Um dos principais frutos obtidos a partir dessas ações (além do caráter de formação já comentado anteriormente) foi um aumento do entusiasmo para lidar com os grandes desafios regionais e o surgimento de novas lideranças na região, sobretudo lideranças femininas. Observou-se um fortalecimento maior do sentido de comunidade para àquela região e maior interação dos atores locais com as instituições.

As ações futuras visam continuar o trabalho dialógico de formação, focando principalmente na construção do Acordo de Gestão da RESEX, fazendo com que os representantes dos pescadores artesanais no Conselho Deliberativo tenham uma assessoria adequada para que a construção desse acordo seja a melhor possível do ponto de vista social e ambiental.

\section{EXTENSÃO, ENSINO E PESQUISA PARA TRANSFORMAÇÃO SOCIAL}

Como relatado anteriormente, o programa extensionista PAPESCA/UFRJ iniciou suas atividades em 2004, na cidade de Macaé, região norte do estado do Rio 
Revista Tecnologia e Sociedade, Curitiba, v. 11, n. 22, 2015

Edição Especial XII Encontro Nacional de Engenharia e Desenvolvimento Social

ISSN (versão online): 1984-3526

ISSN (versão impressa): 1809-0044

de Janeiro, com a participação conjunta de profissionais de diversas áreas do conhecimento, ou seja, saberes científicos e tradicionais que gradativamente denotaram a atual implementação de uma disciplina de extensão voltada para a graduação e oferecida no Centro de Tecnologia da Universidade Federal do Rio de Janeiro - CT/UFRJ.

Entre as metas do programa está a contribuição para a educação continuada e para a conservação das comunidades de pesca artesanal, fazendo com que seja colocada como pauta a ativação dos commons locais.

Com o objetivo de contribuir, entre outras coisas, para a sustentabilidade da cadeia produtiva da pesca na região e o fortalecimento das práticas de integração de saberes em uma perspectiva de construção interdisciplinar, todas as atividades têm com enfoque nas áreas de Organização de Trabalho, Ecologia, Beneficiamento de Pescado e Aquicultura e Economia Solidária.

A PAPESCA/UFRJ, entre 2004 e 2007, contribuiu com a estratégia pedagógica politécnica que orientou o Colégio Municipal dos Pescadores de Macaé - parceria entre a Prefeitura Municipal de Macaé e a UFRJ - oferecida a estudantes do ciclo fundamental, - que compreende alunos do

quinto ao nono ano, - e também alfabetização de jovens e adultos (EJA) dando corpo ao projeto de desenvolvimento local, social e solidário na cidade de Macaé.

Quando do seu início, a atividade pesqueira foi considerada o foco do projeto, por fazer parte da cultura local e por envolver um número significativo de cidadãos na contextualização de diversas questões. Essas por sua vez, dizem respeito não só à pesca, como também à preservação

do meio ambiente, à tecnologia na construção de embarcações, à dinâmica e à segurança da navegação e às relações de trabalho e renda.

As peculiaridades que englobam as comunidades tradicionais vão desde os modos de produção até a geração de conflitos de interesses na utilização da área marinha. Assim como em Itaipu, Macaé ou qualquer outra região costeira no Brasil, também há uma evidente queda e desordenamento na oferta de peixes, além de serem comuns outros entraves de ordens diversas, principalmente aqueles políticos. Neste sentido a práxis extensionista, assim concebida, possui potencialidade para o 
Revista Tecnologia e Sociedade, Curitiba, v. 11, n. 22, 2015

Edição Especial XII Encontro Nacional de Engenharia e Desenvolvimento Social

ISSN (versão online): 1984-3526

ISSN (versão impressa): 1809-0044

desenvolvimento das competências profissionais e de sensibilização humana de docentes, discentes e outros atores sociais.

Apesar de ser ponto crucial para a realização dos projetos participativos, em sua maioria, as atividades atreladas à extensão costumeiramente estão distanciadas dos currículos formais dos alunos de graduação e limitadas a eventos pontuais e de continuidade abreviada. Diante disso, a institucionalização das ações extensionistas, deve ser objeto constante de análise e pesquisa na adequação à proposta de indissociabilidade da extensão na política das Instituições Federais de Ensino.

Nesse sentido, é meritória tanto a Meta 23 do Plano Nacional de Educação (2001-2010), que indica a reserva mínima de dez por cento do total de créditos exigidos para a graduação no ensino superior no País, para a atuação dos estudantes em atividades de extensão (Lei Federal 10.172/2001), como também a Meta 12.7 do novo Plano Nacional de Educação (2011-2020), aprovado, em 2014, pelo Congresso Nacional. Foi a partir desse amparo legal que a Pró-Reitoria de Extensão da UFRJ liderou a comunidade acadêmica, a qual fez aprovar a Resolução 3/2013 do Conselho de Ensino de Graduação, que em seu primeiro artigo determina "a realização de atividades de extensão é obrigatória para todos os estudantes dos cursos de graduação da UFRJ, devendo estar previsto um mínimo de dez por cento de carga horária em atividades de extensão nos respectivos currículos, em relação ao total de créditos a serem cursados". Tal resolução deu base para uma mobilização institucional para oferta de disciplinas de extensão na universidade, tal qual as disciplinas da Escola Politécnica da UFRJ, no âmbito dos Projetos de Extensão em Engenharia. Neste bojo, o SOLTEC contribuiu com a criação de seis delas, dentre as quais se destaca, a disciplina EEWX02 - PAPESCA Pesquisa Ação na Cadeia Produtiva da Pesca no Litoral Fluminense.

Essa disciplina é oferecida desde o início e 2013, e conta com a participação de bolsistas e estudantes de graduação ou pós-graduação regularmente inscritos e de diferentes cursos e campi, como o da Praia Vermelha - Serviço Social e Biblioteconomia; do IFCS - Ciências Sociais e História; da Cidade Universitária Engenharia de Produção, Engenharia Metalúrgica, Engenharia de Alimentos, LetrasLiteraturas e Gestão Pública e, do campi da UFRJ em Macaé - Biologia e Nutrição.

Logo, além de fortalecer a integração inter e multidisciplinar na construção de conhecimentos, contribui-se para a construção de referenciais teóricos empíricos 
Revista Tecnologia e Sociedade, Curitiba, v. 11, n. 22, 2015

Edição Especial XII Encontro Nacional de Engenharia e Desenvolvimento Social

ISSN (versão online): 1984-3526

ISSN (versão impressa): 1809-0044

orientados em sala de aula e nos trabalhos de campo por professores e técnicos educacionais da UFRJ.

Além da integração de pesquisadores e técnicos aliados a um apoio institucional amplo, com envolvimento de laboratórios e técnicos efetivos que seguramente possibilitam uma maior inserção nos trabalhos de campo com as comunidades envolvidas.

Busca-se permanentemente a realização de uma análise sobre os desdobramentos da aplicação da disciplina em questão. Conforme trabalho apresentado no $X$ Congresso de Extensão da UFRJ; PAPESCA uma disciplina de extensão em implementação conferiu-se que a sistematização dos dados referentes a atividade extensionista dos alunos permite que se elenquem potencialidades favoráveis à prática das ações e, com isso, aprimora-se o fortalecimento de canais de comunicação que atendam a proposta participativa da disciplina específica de extensão.

Apesar do diagnóstico, fruto de uma pesquisa qualitativa com os alunos matriculados na disciplina no período 2013.2 ter acenado para o fato de que existem limites e potencialidades inerentes à boa qualidade do ato comunicativo entre docentes, discentes e cidadãos das comunidades envolvidas, é de fundamental importância a participação ativa de todos os entes envolvidos na extensão, quer seja institucionalmente ou enquanto prática, contribuindo de maneira efetiva para as adequações curriculares que se fizerem necessárias.

Caracterizada pelo perfil diferenciado, a referida disciplina, assim como o programa PAPESCA/UFRJ, propõe uma postura participativa (protagonista) e coletiva dos alunos na elaboração do conhecimento enquanto meio para aproximar o ensino às exigências da realidade social. Fazer cumprir, portanto, que a universidade seja síntese do tripé ensino, pesquisa e extensão, como preconizado na Constituição da República de 1988, e que na Lei Federal o․ 9.394/96 define, entre outras finalidades, que a educação superior tem como função "promover a extensão, aberta à participação da população, visando à difusão das conquistas e benefícios resultantes da criação cultural e da pesquisa científica e tecnológica geradas pela instituição" - Inciso VII do artigo 43 - ,e que "a educação superior abrangerá cursos e programas, entre os quais, os de extensão, abertos a candidatos de acordo com requisitos da instituição" - inciso IV do artigo 44. 
Revista Tecnologia e Sociedade, Curitiba, v. 11, n. 22, 2015

Edição Especial XII Encontro Nacional de Engenharia e Desenvolvimento Social

ISSN (versão online): 1984-3526

ISSN (versão impressa): 1809-0044

À partir da análise de deliberações dos Conselhos Superiores de Educação das Instituições Federais de Ensino Superior percebeu-se uma preocupação que se dá, em maior ou menor intensidade, de acordo com as resoluções determinadas aos Centros ou Unidades de Ensino com a adequação e o comprometimento das instituições, no sentido de que se garanta a inclusão de $10 \%$ da carga horária a ser cumprida pelo corpo discente na sua formação em atividades de extensão para todos os cursos, as quais que, na UFRJ, estão distribuídas em Requisitos Curriculares Suplementares - RCS e em Requisitos Curriculares Complementares RCC.

O escopo de análise realiza-se, a priori, por meio de metodologias participativas de pesquisa, trabalhos de campo, revisão bibliográfica e entrevistas com alunos e professores integrantes da disciplina supra citada e com realizadores de projetos que são desenvolvidos de forma dialógica e interdisciplinar com estudantes da graduação e de pós-graduação, professores universitários, além de representantes do setor público, do setor privado e das comunidades tradicionais locais.

Tal característica confere ao programa PAPESCA/UFRJ a oportunidade de aprofundar e redefinir o seu referencial teórico, materializados em relatórios, artigos, projetos de graduação, dissertaçõese teses. Dentre os procedimentos, elenca-se também, aqueles que englobam a análise comparativa entre os materiais produzidos, sobretudo os oriundos do desenvolvimento da pesquisa-ação nas comunidades envolvidas, por ora, pescadores da Praia de Itaipu-Niterói, aquicultores familiares da Praia da Rasa em Búzios e pescadores da Baía de Guanabara, em consonância com a formação acadêmica pretendida.

Percebe-se que, apesar da multidisciplinariedade da proposta, os saberes processados (tácitos, populares, científicos) inferem algum grau de contribuição na formação geral, ainda que limitados pelo caráter da oferta - que se restringe ao Centro Tecnológico da UFRJ. Contudo, a atividade de extensão deve ir para além das salas de aula e dos laboratórios, assumindo o compromisso de conhecer a realidade para transformá-la através da síntese dos conhecimentos. Promover essas ações de forma planejada e institucionalizada é de grande valia para o aprimoramento acadêmico, humano e social, por estabelecer importantes espaços de vivências extracurriculares, atreladas à realidade. 
Revista Tecnologia e Sociedade, Curitiba, v. 11, n. 22, 2015

Edição Especial XII Encontro Nacional de Engenharia e Desenvolvimento Social

ISSN (versão online): 1984-3526

ISSN (versão impressa): 1809-0044

Logo, o caráter interdisciplinar que é gerado pela oferta de disciplinas como essa, viabiliza a atuação e compreende a participação de alunos de diversos cursos, ampliando ainda mais as potencialidades extensionistas. Ademais, propicia a transformação dos sujeitos envolvidos na articulação de atividades que contribuem, como neste caso, para atualizar e garantir a sustentabilidade da tradição na cadeia produtiva da pesca artesanal e aquicultura familiar no litoral fluminense.

\section{CONSIDERAÇÕES FINAIS}

A trajetória da PAPESCA/UFRJ é marcada pelo desenvolvimento de metodologias dialógicas e interdisciplinares envolvendo estudantes e professores de graduação e pós-graduação, funcionários do setor público, de organizações não governamentais e cidadãos de comunidades tradicionais, entre outros.

Os projetos desenvolvidos no âmbito da PAPESCA/UFRJ conferiram ao programa a oportunidade de aprofundar e redefinir o seu referencial teórico metodológico, materializados em relatórios, artigos, projetos de graduação como a oferta de uma disciplina específica de extensão, dissertações e teses.

Diante disso, a institucionalização de ações extensionistas, como a implementação de disciplinas específicas de extensão como a PAPESCA/UFRJ, oferecida pela Escola Politécnica da UFRJ, prevista nas edições supracitadas do programa de extensão da UFRJ e do MEC (PROEXTMEC), merece ser objeto de observação e de pesquisa.

A extensão caracteriza-se como uma prática com a sociedade, possibilitando um elo entre academia e as demandas e necessidades sociais, nas elaborações de políticas públicas de ensino e pesquisa que partam de premissas dialógicas, de dignidade, de respeito e solidariedade à comunidade envolvida. O próprio Plano Nacional de Extensão sugere a associação dos processos educativos com ações culturais e científicas aplicadas à realidade. A priori, é possível afirmar que o projeto ainda está se delineando enquanto proposta de ações e que o pescador é muito mais do que uma identidade, é um modo de se relacionar com o espaço, onde os saberes tradicionais têm grande potencial de priorizar tomadas de decisões sobre usos e compartilhamentos do mesmo.

Conclui-se também que a qualidade do ato comunicativo entre discentes e 
Revista Tecnologia e Sociedade, Curitiba, v. 11, n. 22, 2015

Edição Especial XII Encontro Nacional de Engenharia e Desenvolvimento Social

ISSN (versão online): 1984-3526

ISSN (versão impressa): 1809-0044

suas Unidades, e, destas com as comunidades, é considerada regular pela maioria dos alunos que participam e fazem extensão ao longo de seus cursos. Salienta-se que se faz necessário aprimorar a comunicação entre academia e a sociedade de modo a contribuir com o fortalecimento daqueles canais já existentes, além da proposta de criação de outros que sejam pertinentes à qualificação deste diálogo enquanto prática metodológica.

As ações que vem sendo desenvolvidas, há uma década, pela PAPESCA/UFRJ de forma dialógica com os atores sociais comunitários e no âmbito da Pesquisa-Ação, só reforçam a necessidade de se ampliar a atuação das instituições de ensino superior com foco nas demandas da sociedade, a partir de um novo olhar sobre os diferentes saberes existentes. O potencial transformador, tanto para a formação dos acadêmicos, quanto na vida das comunidades em que se desenvolvem as ações do Programa, são incríveis, e mostram que a atuação conjunta entre o saber consuetudinário e o acadêmico, podem gerar frutos transformadores para a sociedade.

\section{REFERÊNCIAS}

ACSERALD, H. - 2010 - Mediação e Negociação de Conflitos Socioambientais. Palestra proferida na Abertura do IX Encontro Temático da 4a Câmara de Coordenação e Revisão do Ministério Público Federal,Brasília. 22/09/2010

ANDRADE, J; THÉ, AP. Relatório do "10 Seminário Redes Solidárias na Cadeia Produtiva da Pesca: sistematizando lições aprendidas no Alto-Médio São Francisco/MG e Macaé/RJ". realizado nos dias 08, 09 e 10 de dezembro Pirapora MG, 2006

ANDRADE, J; MACIEL, VF (coordenadores) Relatório do Seminário de Construção do Projeto Educacional da Rede Solidária da Pesca. Rio de Janeiro, 2009

ANDRADE, J; ADDOR, $\mathrm{F}$ et al. (relatores). Tecendo as costuras de nossa rede. Relatório do IV Seminário da Rede Solidária da Pesca Manaus Amazonas. 2010

ADDOR, F; LIANZA, S LOPES, VF Uma reflexão sobre o papel da universidade em projetos de mobilização política: o caso da Rede Solidária da Pesca. Anais do XX Congresso Brasileiro de Extensão Universitária Belo Horizonte. 2009

BERKES, F, COLDING, J FOLKE, C, Navigating social ecological systems -building resiliences for complexity and Change. Cambridge: Cambridge University Press, 2006

CAPRA, F. A Teia da Vida - Uma nova compreensão científica dos sistemas vivos. São Paulo: Cultrix, 1997 
Revista Tecnologia e Sociedade, Curitiba, v. 11, n. 22, 2015

Edição Especial XII Encontro Nacional de Engenharia e Desenvolvimento Social

ISSN (versão online): 1984-3526

ISSN (versão impressa): 1809-0044

CATTANI, AD (org) A outra economia. Porto Alegre: Veraz, 2003

DIEGUES, A. C.; MOREIRA, A. C. C. (org). Espaços e Recursos Naturais de Uso Comum. NUPAUB/LATROP, 2001.

FEENY, D. et al. A tragédia dos comuns: vinte e dois anos depois in: DIEGUES, A.C.; MOREIRA, A.C.C. (org). Espaços e Recursos Naturais de Uso Comum. NUPAUB/LATROP. 2001, p: 17-42

FREIRE, P. Pedagogia da Autonomia: saberes necessários a prática educativa. 34a ed. São Paulo: Paz e Terra, 1996.

GOLDMAN M. O. Inventando os comuns: teorias e práticas: teorias e práticas do profissional em bens comuns. in DIEGUES, A.C; MOREIRA, A.C.C (org). Espaços e Recursos Naturais de Uso Comum. NUPAUB/LATROP. 2001, p: 43-77

GUNDERSON, L.H.; HOLLING, C.S. Panarchy -understanging transformations in human and natural systems. Island Press. Washington, 2002.

HARDIN, G. The tragedy or the commons. SCIENCE. vol.162. 1968, p 1241-1248.

LIANZA, S \& ADDOR, F (org). Tecnologia e desenvolvimento social e solidário Coleção sociedade e solidariedade. Porto Alegre: Editora UFRGS/SOLTEC, 2005

LIANZA, S; CARNEIRO, AM; MACIELVF; RUTIKOWSKI, J. Pré-diagnóstico para o desenvolvimento sustentável de empreendimentos solidários Relatório da visita técnica da equipe SOLTEC/UFRJ ao Projeto "Peixes Pessoas e Água" na região do Alto-médio São Francisco - 12 a 18 de agosto de 2006

LIANZA, S ADDOR F \& LOPES, VF M. Experiência de Construção da Rede Solidária da Pesca. Anais do VI Encontro Internacional de Economia Solidária - Economia Solidária e Modelo de Desenvolvimento. São Paulo:NESOL/USP, 2008

LIANZA, S.; ADDOR, F.; MACIEL,V. F. A Experiência de Construção da Rede Solidária da Pesca. Anais do IV Encontro Internacional de Economia Solidária, 2009.

NEDER, R.T. Crise socioambiental: estado e sociedade civil no Brasil. Annablume. FAPESP, 2002.

OSTROM, E. Governing the Commons - The Evolution of Institutions for Collective Action. Cambrige Univestiy Press, 2008(22nd printing) (1990 1st edition).

RIBEIRO, C.W.(org). Práticas sócio ambientais na pós graduação brasileira. Editora Anablume, 2010.

RICOVERI, G. Beni Comuni Vs Merci. Jaca Book, 2010

SACHS, I. Rumo à ecossocioeconomia - teoria e prática do desenvolvimento. Paulo Freire Vieira (org). Editora Cortez, 2007.

VIEIRA, P.F,; Berkes, F.; SEIXAS, C. Gestão Integrada e Participativa de Recursos Naturais - conceitos, métodos e experiências. APED. Florianópolis, 2005. 